Development, characterization and application of an improved online reactive oxygen species analyzer based on MARGA

\author{
Jiyan $\mathrm{Wu}^{1,2}$, Chi Yang ${ }^{1,2}$, Chunyan Zhang ${ }^{1,2}$, Fang Cao ${ }^{1,2}$, Aiping $\mathrm{Wu}^{1,2}$, Yanlin Zhang ${ }^{1,2}$ \\ * \\ 1 Yale-NUIST Center on Atmospheric Environ., Joint International Research \\ Laboratory of Climate and Environment Change (ILCEC), Nanjing University of \\ Information Science and Technology, Nanjing 210044, China \\ ${ }^{2}$ School of Applied Meteorology, Nanjing University of Information Science and \\ Technology, Nanjing 210044, China \\ Correspondence: Yanlin Zhang (zhangyanlin@,nuist.edu.cn)
}

\begin{abstract}
Excessive reactive oxygen species (ROS) in the human body is an important factor leading to diseases. Therefore, research on the content of reactive oxygen species in atmospheric particles is necessary. In recent years, the online detection technology of ROS has been developed. However, there are few technical studies on online detection of ROS based on the DTT method. Here, to modify the instrument, it is added a DTT experimental module that is protected from light and filled with nitrogen at the end, based on the Monitor for AeRosols and Gases in ambient Air (MARGA). The experimental study found that the detection limit of the modified instrument is 0.024 $\mathrm{nmol} \mathrm{min}^{-1}$. And the accuracy of the online instrument is determined by comparing the online and offline levels of the samples, which yielded good consistency (slope 0.97, $\mathrm{R}^{2}=0.95$ ). It shows that the performance of the instrument is indeed optimized, the instrument is stable, and the characterization of ROS is accurate. The instrument not only realizes the online detection conveniently and quickly, but also achieves the hourby-hour detection of ROS based on the DTT method. Meanwhile, reactive oxygen and inorganic ions in atmospheric particles are quantified using the online technique in the northern suburbs of Nanjing. It is found that the content of ROS during the day is higher than that at night, especially after it rains, ROS peaks appear in the two time periods of 08:00-10:00 and 16:00-18:00. In addition, examination of the online ROS and watersoluble ions $\left(\mathrm{SO}_{4}{ }^{2-}, \mathrm{NO}_{3}{ }^{-}, \mathrm{NH}_{4}{ }^{+}, \mathrm{Na}^{+}, \mathrm{Ca}^{2+}, \mathrm{K}^{+}\right), \mathrm{BC}$ and polluting gases $\left(\mathrm{SO}_{2}, \mathrm{CO}, \mathrm{O}_{3}\right.$, $\mathrm{NO}, \mathrm{NO}_{\mathrm{x}}$ ) measurements revealed that photo-oxidation and secondary formation processes could be important sources of aerosol ROS. This method breakthrough enables the quantitative assessment of atmospheric particulate matter ROS at the diurnal scale, providing an effective tool to study sources and environmental impacts of ROS.
\end{abstract}

\title{
1、Introduction
}

Air quality is a major issue affecting human health, and prolonged exposure to high ambient particulate concentrations can lead to a significant increase in the probability of respiratory and cardiovascular diseases, which can seriously impair human health (Delfino et al., 2005; Ghio et al., 2012; Pöschl and Shiraiwa, 2015). The production of reactive oxygen species (ROS) in the human body is the most reliable 
pathophysiological mechanism proposed, and excessive reactive oxygen species can cause an imbalance between the oxidative system and the antioxidant system, causing oxidative stress and tissue damage (Ahmad et al., 2021; Akhtar et al., 2010; Borm et al., 2007; Delfino et al., 2013; Lodovici and Bigagli, 2011). Thus, oxidative potential (OP) has been proposed as a more biologically relevant indicator than particulate matter (PM) mass concentration to represent the combined effects of multiple toxic components in PM (Ayres et al., 2008; Hellack et al., 2015; Janssen et al., 2015). Understanding the generation mechanism and source characteristics of reactive oxygen species is essential for making reasonable pollution control decisions and reducing their impact on human health.

In recent years, the analysis method of oxidation potential has cell detection and cell-free detection. To provide a simpler and quicker way to determine the oxidation potential of environmental particulate matter, cell-free methods such as electron spin (or paramagnetic) resonance $\left(\mathrm{OP}_{\mathrm{ESR}}\right)$, dithiothreitol assay $\left(\mathrm{OP}_{\mathrm{DTT}}\right)$, ascorbic acid assay $\left(\mathrm{OP}_{\mathrm{AA}}\right)$, high-performance liquid chromatography (HPLC) and glutathione assay $\left(\mathrm{OP}_{\mathrm{GSH}}\right)$ are often used as the main measurement methods for ROS (Bates et al., 2019; Ghio et al., 2012). Through the comparison and analysis of these various methods by a large number of researchers, the DTT method is generally considered to be the most common and comprehensive method to reflect the magnitude of the chemical oxidation potential of particulate matter (Hedayat et al., 2014; Xiong et al., 2017).

Generally, the cell-free method still has problems with detection delays and degradation of particulate chemical components during sample storage, which not only leads to inaccurate detection data, but also the inability to capture daily changes. Therefore, the development of online detection technology becomes necessary (Charrier et al., 2016; Dou et al., 2015; Fang et al., 2017; Li et al., 2012; Liu et al., 2014; Velali et al., 2016; Vreeland et al., 2017). So far, the development of online detection technology is mainly based on the DCFH method and the DTT method. On the one hand, an online detection technology based on the DCFH method has been reported previously (Eiguren-Fernandez et al., 2017; Huang et al., 2016; Sameenoi et al., 2012; Wragg et al., 2016). However, some researchers believe that in the DCFH method, the horseradish peroxidase (HRP) will promote the production of hydroxyl free radicals, leading to an overestimation of ROS content (Pal et al., 2012). On the other hand, based on the DTT method to develop online detection technology (Fang et al., 2014; Puthussery et al., 2018), The semi-automatic detection system researched by Fang et al, based on the DTT method cannot realize an online collection of environmental samples. On this basis, Puthussery et al used a mist chamber (MC) to continuously collect $\mathrm{PM}_{2.5}$ in environmental water and realized fully automatic hourly ROS detection.

However, these detection methods ignore the influence of air and light on the experiment. As the main reagent of the experiment, dithiothreitol (DTT) and 5,5'dithiobis (2-nitrobenzoic acid) (DTNB) are easily oxidized by air (Chen et al., 2010). Therefore, this experiment is optimized based on the research of Fang et al and Puthussery et al. We achieve accurate measurement of the oxidation potential of environmental particulates by shielding from light and filling with nitrogen. In addition, the present study is developed on the basis of the MARGA, which is a reliable field 
instrument. And it is not only used in many research institutes for long-term ion observation but also used to transform the observation of low-molecular-weight organic acids in the gas and particle phases (Stieger et al., 2019). MARGA is used to collect particulate matter and is connected to the optimized DTTV detection part to observe the oxidation potential hour by hour. The system realizes simultaneous observation of oxidation potential and inorganic ions. Here, we optimize the performance of the instrument and measure the hourly averaged OP of ambient $\mathrm{PM}_{2.5}$. The reliability of online detection of oxidation potential data is supported by analyzing the correlation between ions, polluting gases, $\mathrm{BC}$ and oxidation potential.

\section{2、Materials and Method}

\subsection{Instrument set-up and improvement}

Figure 1 shows the scheme and schematic diagram of the system for DTT online detection. The instrument is set up in the Atmospheric Environ. monitoring laboratory on the roof of the Wende Building of Nanjing University of Information Engineering (30 $\mathrm{m}$ above the ground) and the room temperature is maintained at $20^{\circ} \mathrm{C}$. The entire system is composed of the MARGA, the automatic sample-receiving device, and the DTT experimental reaction device. The MARGA is used as an instrument for detecting atmospheric aerosols and inorganic components of gases (water-soluble ions $\mathrm{Cl}^{-} 、 \mathrm{NO}_{3}{ }^{-}$、 $\mathrm{SO}_{4}{ }^{2-} 、 \mathrm{NH}_{4}^{+} 、 \mathrm{Na}^{+} 、 \mathrm{~K}^{+} 、 \mathrm{Mg}^{2+} 、 \mathrm{Ca}^{2+}$ ), and it collects gases using a wet rotary separator and aerosols using steam injection, and absorbs gases and aerosols into the aqueous phase separately to separate them from each other. Then, the resulting solution is analyzed by ion chromatography equipped with a conductivity detector. That is, the gas and aerosol are analyzed separately to detect the gas precursors and different ionic compositions in the aerosol.

In the DTT reaction module, to avoid the influence of light and air on the experiment, the DTT experimental part in this experiment was kept in an environment protected from light and flushed into nitrogen. In addition, we added a refrigerator to store DTT, DTNB and other experimental solutions. During the DTT experiment, the reaction tube and mixing tube were placed in an incubator at $37^{\circ} \mathrm{C}$ to simulate the temperature of human lungs. To realize the subsequent DTT experimental reactions, as in Figure 1 we collected the liquid-phase aerosols into sample tubes through a dualchannel split-flow controlled-volume peristaltic pump. And set peristaltic pump 1 speed to $1.55 \mathrm{ml} \mathrm{h}^{-1}$ to finish $1.5 \mathrm{ml} \mathrm{h}^{-1}$ sample volume.

Finally, the determination of DTT activity is achieved by the continuous regular operation of the programmable pumps $\mathrm{A}$ and $\mathrm{B}$ and the detection of the spectrophotometer. (see Sect. 2.2.1 for details)

\subsection{Method}

\subsubsection{Online DTT assay measurement}

The whole measurement step is divided into three steps: sample collection, DTT reaction part, and spectrophotometer detection. In the first step (the sample collection), the MARGA will discharge $25 \mathrm{ml}$ of aerosol liquid every hour, and use the dual-channel split flow control volume peristaltic pump 1 to add $1.55 \mathrm{ml}$ of the solution (to ensure 
$1.5 \mathrm{ml}$ of sample) into the sample tube, and the rest will enter the automatic sampling device to save through the peristaltic pump 2 (the automatic sampler is set to rotate one grid per hour).

In the second step (the part is protected from light and in a nitrogen environment), the reaction part is divided into a DTT oxidation step and a DTT determination step(Wang et al., 2019). First (DTT oxidation step), use pump A to add $5 \mathrm{~mL}$ potassium phosphate buffer $\left(0.1 \mathrm{~mol} \mathrm{~L}^{-1}\right), 1.5 \mathrm{~mL}$ aerosol extract sample, and $0.5 \mathrm{~mL}$ DTT (1 $\mathrm{mmol} \mathrm{L}^{-1}$ ) into the mixing bottle (MV) in sequence. Inhale ultrapure water to clean the syringe of pump A. DTT reacts with the aerosol extract in MV. Second (DTT determination step), after completing the first step, immediately use pump A to pump $1 \mathrm{~mL}$ TCA $(10 \% \mathrm{w} / \mathrm{v}$; quencher) into the reaction flask ( $\mathrm{RV}$, wrap it in aluminum foil to prevent possible Light interference). Then, use pump A to suck the mixed solution in the $1 \mathrm{ml}$ mixing bottle and transfer it to the reaction bottle to mix it with TCA. Add 0.05 $\mathrm{mL}$ DTNB $\left(0.01 \mathrm{mmol} \mathrm{L}^{-1}\right)$ via pump B and mix. The residual DTT reacts with DTNB to form light absorption product 2-nitro-5-thiobenzoic acid (TNB) with high extinction performance at $412 \mathrm{~nm}$.

In the third step, in the detection part of the spectrophotometer, use pump A to add $4 \mathrm{~mL}$ Tris buffer $\left(0.4 \mathrm{~mol} \mathrm{~L}^{-1}\right.$, containing $20 \mathrm{mmol} \mathrm{L}^{-1}$ EDTA) into the reaction flask (RV). After the reaction is completed, use pump A to add the final mixture solution in the reaction flask to the LWCC for the absorbance test. The data acquisition software (Spectra Suite) records the absorbance at 412 and $700 \mathrm{~nm}$ every $10 \mathrm{~min}$ (select the baseline absorbance of TNB). Then, the system uses deionized water (deionized water) for self-cleaning to eliminate any residual liquid in the reaction flask, tubing, syringe, and LWCC. To determine the rate of DTT consumption, the time interval is $10 \mathrm{~min}$, and a total of $6(0 \mathrm{~min}, 10 \mathrm{~min}, 20 \mathrm{~min}, 30 \mathrm{~min}, 40 \mathrm{~min}, 50 \mathrm{~min})$ data points of DTT concentration over time are generated. Finally, the automated system performs the selfcleaning procedure again to ensure that there is no residue, and the system repeats the above operations in the next hour to realize hourly detection of DTT activity.

$$
\begin{gathered}
\Delta D T T=-\sigma A b s \cdot \frac{N_{0}}{A b s_{0}} \\
D T T v=\frac{\Delta D T T_{s}\left(n m o l ~ \mathrm{~min}^{-1}\right)-\Delta D T T_{b}\left(n m o l ~ \mathrm{~min}^{-1}\right)}{V_{t}\left(\mathrm{~m}^{3}\right) \times \frac{V_{S}(m L)}{V_{e}(m L)}}
\end{gathered}
$$

where $\sigma \mathrm{Abs}$ is the slope of absorbance versus time; $\mathrm{Abs}_{0}$ is the initial absorbance calculated from the intercept of the linear regression of absorbance versus time; and $\mathrm{N}_{0}$ is the initial moles of DTT added in the reaction vial. $\triangle D T T_{s}\left(\mathrm{nmol} \mathrm{min}^{-1}\right)$ is the $D T T_{v}$ consumption rate of the sample, $\Delta D T T_{b}\left(\mathrm{nmol} \mathrm{min}{ }^{-1}\right)$ is the blank DTT consumption rate, $V_{t}\left(m^{3}\right)$ is the sampling volume corresponding to the sample, and $V_{s}(\mathrm{~mL})$ is the injection volume, $V_{e}(\mathrm{~mL})$ is the sampling volume.

\subsubsection{Online DTT instrument performance}

The performance of the automated system is characterized by testing to determine the instrument response, limit of detection (LOD), precision and accuracy, while using a large flow sampler to collect samples for offline and online comparative analysis. (See Sect.3.1 for details)

We perform DTT activity detection and comparison on samples collected by 9,10 - 
phenanthraquinone (PQN) and traditional high-flow samplers. First, we select PQN with concentrations of $0.01,0.02,0.025,0.05,0.085 \mathrm{nmol} \mathrm{L}^{-1}$ to compare online and offline DTT activity detection to determine the error of online and offline experiments. Secondly, select 10 traditionally collected samples for online and offline comparison, and then combine the experimental error between online and offline determined by PQN (PQN online and offline orthogonal fitting) to analyze the accuracy of online and offline.

\subsubsection{Instrument maintenance}

DTT and DTNB solutions are prepared once every 4 days, and the rest of the solutions are prepared according to the amount. Before each test, perform an overall light-proof and nitrogen bag inspection. The standard curve was measured once before each experiment. PQN is calibrated online and offline ever month. Clean the instrument pipeline once a week, 5 times each time (Ultra-pure water).

\subsection{Collection and preparation of environmental samples}

The sampling point is located on the roof of the seventh floor of the Maintenance Branch ( $\left.34^{\circ} 58^{\prime} \mathrm{N}, 117^{\circ} 26^{\prime} \mathrm{E}\right)$ of the Power Company, Yunlong District, Xuzhou City. The surrounding buildings mainly include auto repair shops, logistics centers, pharmaceutical factories, and large residential areas and farmland. A large flow $\mathrm{PM}_{2.5}$ sampler (KC-6120) is used for continuous sampling, and a total of 10 samples are collected (October 21, 2018-October 31, 2018). When sampling, the flow rate is $1.0 \mathrm{~m}^{3}$ $\mathrm{min}^{-1}$, and each sampling time is $24 \mathrm{~h}$; in this study, we collected samples using quartz filters and stored them in a refrigerator at $-26^{\circ} \mathrm{C}$. Before the start of the experiment, the collected samples were subjected to extraction processing, and a sample film with a diameter of $16 \mathrm{~mm}$ is cut into a brown glass bottle, $5 \mathrm{ml}$ ultrapure water is added to shake for $30 \mathrm{~min}$, and filtered with a $0.22 \mu \mathrm{m}$ PTFE syringe filter to remove insoluble substances.

\section{Results and discussion}

\subsection{Instrument performance}

\subsubsection{Improvement of the instrument}

As we all know, photo-oxidation promotes the generation of ROS (Fang et al., 2016; Visentin et al., 2016; Yang et al., 2014). In addition, during the measurement process, the ingress of air inside the instrument will also cause the DTT activity to increase. Therefore, before on-site deployment, the online DTT inspection instrument was optimized by filling in nitrogen gas and shielding the whole from light. And respectively detect the DTT consumption rate $(\triangle \mathrm{DTT})$ of 10 blanks (ultra-pure water) before and after optimization. As shown in Figure 2, before the system optimization, we found that the average $\Delta$ DTT measured by 10 blanks was $0.25 \pm 0.04 \mathrm{nmol} \mathrm{min}{ }^{-1}$, and there is a big fluctuation. After optimization, the average $\Delta \mathrm{DTT}$ is $0.14 \pm 0.008 \mathrm{nmol}$ $\min ^{-1}$, which is significantly lower than system optimization. Moreover, the standard deviation (0.008) is much smaller than Puthussery et al (0.08) and Fang et al (0.103) (Fang et al., 2014; Puthussery et al., 2018). It shows that air and light do promote the generation of ROS, and the nitrogen environment and avoiding light contribute to the 
stability of the system. The optimized system is more accurate in measuring the oxidation potential of environmental particulate matter. To further prove the optimization effect, the performance of the instrument is studied. (See Sect.3.1.4 for details)

\subsubsection{Calibration of DTT $v$ measurement and analysis system}

In past studies, PQN is often used as a standard sample of atmospheric particulate matter (Charrier and Anastasio, 2011; Charrier and Anastasio, 2015; Xiong et al., 2017). The analytical measurement part of the online DTT instrument is calibrated by measuring the DTT activity of PQN at different concentrations. As shown in Figure 3, the linear graph of DTT consumption rate and PQN concentration, the online detection slope is $3.66 \pm 0.26$, and the coefficient $\mathrm{R}^{2}=0.992$. The calibration slope is less than the slope obtained by the automatic DTT system of Fang et al. (2015) and Puthussery et al (2018). This also shows that shielding from light and filling with nitrogen will reduce DTT consumption, and it also supports the accuracy of the system in determining the oxidation potential of environmental particulates. During the on-site operation, PQN's online and offline testing is measured at least once a month to ensure online accuracy.

\subsubsection{Limit of detection and precision}

The limit of detection (LOD) of the system is defined as 3 times the standard deviation of the deionized water blank $(\mathrm{N}=23)$, which is $0.024 \mathrm{nmol} \mathrm{m^{-1 }}$. To ensure the accuracy of the system, the deionized water blank samples are taken once a day (14 days) during the sampling period, besides the 10 continuously measured during the optimization of the system.

Use deionized water to evaluate the accuracy of the environmental sample automation system and analyze the DTT activity. The low standard deviation (coefficient of variation, $\mathrm{CV}=5.61 \%$ ) of $0.024 \mathrm{nmol} \mathrm{min}^{-1}$ indicates that the system has sufficiently high accuracy for environmental samples.

\subsubsection{Accuracy}

The accuracy of the system is verified by comparing the DTT activity of the positive control and environmental particulate samples obtained from the automated method with the results obtained from the same experimental protocol performed manually. (Cho et al., 2005)

Five concentrations of PQN solutions $\left(0.01,0.02,0.025,0.05,0.085 \mathrm{nmol} \mathrm{L}^{-1}\right)$ are run in the automatic system, which is very close to the results of the manual system (the standard deviation of the automatic system is kept at $0.008 \mathrm{nmol} \mathrm{min}{ }^{-1}$, and the coefficient of variation is $2.28 \%$; the standard of the manual system The difference is $0.0044 \mathrm{nmol} \mathrm{min}{ }^{-1}$, the coefficient of variation is $1.48 \%$ ). As shown in Figure 4, the slope (manual/automatic) obtained by orthogonal fitting is 1.14 , the intercept is 0.12 , and the correlation coefficient $\left(\mathrm{R}^{2}\right)$ is 0.997 . To ensure the high accuracy of the online system and the offline system, as a further verification, we used online and offline manual methods to conduct DTT activity analysis on ten environmental particulate matter samples.

We use the PQN online and offline DTT consumption rate orthogonal fitting result as the system to correct the error, as shown in Figure 5, through the offline and online orthogonal fitting of 10 environmental particulate matter samples before and after the 
error correction. We found that the corrected results are better (the slope is 0.97 closer to 1 , the intercept is 0.05 closer to $0, \mathrm{R}^{2}=0.954$ ), which is significantly better than the results of Puthussery et al. The good agreement between the two sampling systems indicates that the DTT measurement of environmental samples has high overall accuracy. These tests also proved the necessity of optimization.

\subsection{DTT activity of ambient samples}

The volume-normalized oxidation potential $\mathrm{DTT}_{\mathrm{V}}$ is used as an index of exposure to inhaled air to point out the inherent ability of particles to deplete relevant antioxidants. During the observation period, the daily change of DTTV in Nanjing is shown in Figure 6. The average $\mathrm{DTT}_{\mathrm{V}}$ is $0.83 \pm 0.38 \mathrm{nmol} \mathrm{min} \mathrm{m}^{-1}$. Compared with Beijing's $\mathrm{DTT}_{\mathrm{V}}$ in the spring of 2012 (urban area: $0.24 \mathrm{nmol} \mathrm{min}^{-1} \mathrm{~m}^{-3}$ )(Liu et al., 2014; Wang et al., 2019). and Zhejiang University's annual DTTV average of $0.62 \mathrm{nmol} \mathrm{min}^{-1} \mathrm{~m}^{-3}$ (Yu et al., 2019), our results are on the high side; And compared with Peking University's 2015 annual $\operatorname{DTT}_{\mathrm{V}}\left(12.26 \pm 6.82 \mathrm{nmol} \mathrm{min}^{-1} \mathrm{~m}^{-3}\right)$ (Perrone et al., 2016)and Guangzhou's In the winter of 2017 (DTT $\mathrm{V}: 4.67 \pm 1.06 \mathrm{nmol} \mathrm{min}^{-1} \mathrm{~m}^{-3}$ ) and in the spring of 2018 (DTT $\mathrm{V}: 4.45 \pm 1.02$ $\mathrm{nmol} \mathrm{min}^{-1} \mathrm{~m}^{-3}$ ), our values are low, which may be related to the current season and emission factors. In addition, we found that the rain during the sampling period caused significant changes in the 24-hour DTTV. To better understand the environmental factors affecting $\mathrm{DTT}_{\mathrm{V}}$, we divided the $\mathrm{DTT}_{\mathrm{V}}$ daily activities. As shown in Figure S2, the daily distribution of 24-hour DTT activities during the entire sampling period (a), before rain (b), during rain (c), and after rain (d) are divided. Figure S2(a) represents the hourly change of DTTV during the entire sample period. We found that the highest value of $\mathrm{DTT}_{V}$ in a day occurs at 11-12 am, and $\mathrm{DTT}_{V}$ is greater during the day than at night, which is similar to the study by Puthussery et al. Before the rain, the average

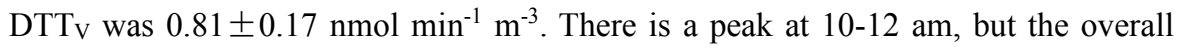
situation is relatively flat, and there is no obvious difference between day and night. And the average value of DTTV during the rain is $0.55 \pm 0.10 \mathrm{nmol} \mathrm{min} \mathrm{m}^{-1} \mathrm{~m}^{-3}$, which decreased significantly. There is no doubt that this is caused by rain settling the polluting components of the atmosphere. In contrast, there is significant daily activity in $\mathrm{DTT}_{V}$ following rain, with peaks occurring mainly between 8-10 am and 4-6 pm, and DTTV $_{V}$ is significantly higher during the day than at night, which is similar to the Puthussery study (Puthussery et al., 2018).

\subsection{The correlation between $\mathrm{PM}_{2.5}$ and polluting gases and ROS activity}

To further study, the daily changes of DTT $_{V}$ and its correlation with various emission sources on site. As shown in Figure 7, we measured the water-soluble ionic components of $\mathrm{PM}_{2.5}\left(\mathrm{SO}_{4}{ }^{2-}, \mathrm{NO}_{3}{ }^{-}, \mathrm{NH}_{4}^{+}, \mathrm{Na}^{+}, \mathrm{Ca}^{2+}, \mathrm{K}^{+}\right), \mathrm{BC}$, and pollution gas $\left(\mathrm{SO}_{2}\right.$, $\mathrm{CO}, \mathrm{O}_{3}, \mathrm{NH}_{3}$ ) content changes. The average concentration of $\mathrm{PM}_{2.5}$ during the sampling period was $9.97 \pm 6.53 \mathrm{ng} \mathrm{m}^{-3}$, the average concentration of $\mathrm{PM}_{2.5}$ before rain was $11.13 \pm 7.21 \mathrm{ng} \mathrm{m}^{-3}$, the average concentration of $\mathrm{PM}_{2.5}$ after rain was $7.80 \pm 4.18 \mathrm{ng} \mathrm{m}^{-3}$, $\mathrm{PM}_{2.5}$ There is a significant drop in concentration. And through correlation analysis, we found that $\mathrm{DTT}_{\mathrm{V}}$ and $\mathrm{PM}_{2.5}$ concentration were positively correlated before rain, but negatively correlated after rain. Therefore, we suspect that the source of DTTV is different before and after the rain. $\mathrm{BC}$ and the polluting gases $\mathrm{SO}_{2}, \mathrm{NO}_{\mathrm{x}}, \mathrm{NO}_{2}, \mathrm{CO}, \mathrm{Ca}^{2+}$, $\mathrm{K}^{+}, \mathrm{Mg}^{2+}$ are often used as tracers of biomass burning, coal combustion, and dust storms. 
The levels of these substances were not high during the sampling period and decreased to varying degrees after rain. It is similar to Liu and Zhang et al who concluded that biomass burning, coal combustion, and dust storms were not major sources of pollution in Nanjing during the summer(Guo et al., 2019; Liu et al., 2019; Zhang et al., 2020). In addition, there was no strong correlation between $\mathrm{DTT}_{\mathrm{V}}$ and $\mathrm{SO}_{2}, \mathrm{NO}_{\mathrm{x}}, \mathrm{NO}_{2}$, and $\mathrm{CO}$ before and after the rain. Therefore, it can be judged that neither biomass burning, coal combustion nor dust is the main source affecting $\mathrm{DTT}_{\mathrm{V}}$. In contrast, we found that there is a significant difference between day and night in $\mathrm{O}_{3}$ after rain, which is similar to the change of DTTV, and after rain, $\mathrm{DTT}_{\mathrm{V}}$ and $\mathrm{O}_{3}$ show a strong correlation $(\mathrm{r}=0.624)$. After it rains, the $\mathrm{O}_{3}$ content in the air environment increases. Under the action of the sun's ultraviolet rays, the $\mathrm{O}_{3}$ is photodegraded to form active oxygen components such as $\mathrm{OH}$ radicals (Ehhalt and Rohrer, 2000; Rohrer and Berresheim, 2006).

To further confirm the influence of light on $\mathrm{DTT}_{\mathrm{V}}$, the day and night correlation analysis of substances related to photo-oxidation $\left(\mathrm{NH}_{4}{ }^{+}, \mathrm{NO}_{3}{ }^{-}, \mathrm{SO}_{4}{ }^{2-}\right)$ and $\mathrm{DTT}_{\mathrm{V}}$ is carried out. As shown in Table $\mathrm{S} 2$, we find that $\mathrm{NH}_{4}{ }^{+}, \mathrm{NO}_{3}{ }^{-}, \mathrm{SO}_{4}{ }^{2-}$ and $\mathrm{DTT}_{\mathrm{V}}$ are significantly correlated during the day $(\mathrm{r}=0.434, \mathrm{r}=0.461, \mathrm{r}=0.263, \mathrm{P}<0.01)$. As far as we know, there is no evidence in the literature that water-soluble inorganic ions $\left(\mathrm{NH}_{4}{ }^{+}\right.$, $\mathrm{NO}_{3}{ }^{-}, \mathrm{SO}_{4}{ }^{2-}$ ) have redox activity in an aerobic environment(Calas et al., 2018; Stevanovic et al., 2017). However, their correlation with DTT $_{V}$ may be due to collinearity with redox-active organic compounds, rather than actual contribution to the oxidation potential of particles. We speculate that the high correlation may be related to the photochemical reactions that occur during the day.

\section{4、Summary and conclusions}

This study proposes and characterizes an improved online active oxygen analyzer. Compared with the previous research, the main improvements(Fang et al., 2014; Puthussery et al., 2018). The optimization analysis is as follows: (1) The experimental environment is processed to isolate the air and avoid light; (2) The sampling method has changed. We use the MARGA online ion analyzer, which is more mature and stable. Compared with before optimization, the standard deviation of the blank was significantly smaller, Thus, the detection limit of the instrument $\left(0.024 \mathrm{nmol} \mathrm{min}{ }^{-1}\right)$ becomes smaller and more stable. The DTT consumption rate is reduced by $24.4 \%$, which eliminates the influence of outside air and light in the experiment. And the consistency between online and offline is improved (slope $=0.97, \mathrm{R}^{2}=0.95$ ), the accuracy of the system is higher.

By changing the $\mathrm{DTT}_{V}$ content hour by hour during the sampling period, we found that the DTT activity during the day is higher than that at night, and it is especially obvious after rain, which is mainly related to the increase in UV radiation during the day after rain. In addition, we analyzed the correlation between water-soluble ions $\left(\mathrm{SO}_{4}{ }^{2-}, \mathrm{NO}_{3}{ }^{-}\right.$, $\mathrm{NH}_{4}{ }^{+}, \mathrm{Na}^{+}, \mathrm{Ca}^{2+}, \mathrm{K}^{+}$), BC, pollutant gases $\left(\mathrm{SO}_{2}, \mathrm{CO}, \mathrm{O}_{3}, \mathrm{NO}, \mathrm{NO}_{\mathrm{x}}, \mathrm{NH}_{3}\right.$ ) and $\mathrm{DTT}_{\mathrm{V}}$, and we found that the main source of influence of OP in the Nanjing environment in summer is daytime Secondary photochemical conversion and ultraviolet radiation. In the future, we hope to add more experimental modules to the back-end based on the MARGA sample collection device to realize the diversification of detection compositions. In addition, the system can be combined with other substance detection 
345 instruments. It will achieve the daily contribution of various emission sources to the 346 risk associated with OP exposure can be inferred from other species. 
348 Data availability. Data used in this paper can be provided upon request by email to 349 ZYL (dryanlinzhang@outlook.com).

350 Author contributions. WJY designed the instrument, led the sampling campaign, 351 performed the experiments, and wrote the manuscript. YC participated in experimental 352 design and guided the experimental process. ZCY chose the building address and 353 initially built the instrument. CF helped in the filter collection and in conducting the 354 DTT activity experiments. ZYL conceived the idea, organized the manuscript, and 355 supervised the project.

356 Competing interests. The authors declare that they have no conflict of interest.

357 Acknowledgements. The authors thank funding support from the National Nature 358 Science Foundation of China (Nos. 41977305), the Natural Science Foundation of 359 Jiangsu Province (No. BK20180040), the fund from Jiangsu Innovation \& 360 Entrepreneurship Team. 
References:

Ahmad, M., Yu, Q., Chen, J., Cheng, S., Qin, W., and Zhang, Y.: Chemical characteristics, oxidative potential, and sources of PM (2.5) in wintertime in Lahore and Peshawar, Pakistan, J Environ Sci (China), 102, 148-158, https://doi.org/10.1016/j.jes.2020.09.014, 2021. proinflammatory effects of ambient and source-related particulate matter (PM) in relation to the production of reactive oxygen species (ROS) and cytokine adsorption by particles, Inhal Toxicol, 22 Suppl 2, 37-47, https://doi.org/10.3109/08958378.2010.518377, 2010. Ayres, J. G., Borm, P., Cassee, F. R., Castranova, V., Donaldson, K., Ghio, A., Harrison, R. M., Hider, R., Kelly, F., Kooter, I. M., Marano, F., Maynard, R. L., Mudway, I., Nel, A., Sioutas, C., Smith, S., BaezaSquiban, A., Cho, A., Duggan, S., and Froines, J.: Evaluating the toxicity of airborne particulate matter and nanoparticles by measuring oxidative stress potential--a workshop report and consensus statement, Inhal Toxicol, 20, 75-99, https://doi.org/10.1080/08958370701665517, 2008. matter: from biologically effective dose to a promising, novel metric, Occup Environ Med, 64, 73-74, https://doi.org/10.1136/oem.2006.029090, 2007. C., Oliete, A., Jacob, V., Besombes, J. L., Chevrier, F., and Jaffrezo, J. L.: Comparison between five acellular oxidative potential measurement assays performed with detailed chemistry on PM10 samples from the city of Chamonix (France), Atmos. Chem. Phys., 18, 7863-7875, https://doi.org/10.5194/acp18-7863-2018, 2018.

Charrier, J. G. and Anastasio, C.: Impacts of Antioxidants on Hydroxyl Radical Production from Individual and Mixed Transition Metals in a Surrogate Lung Fluid, Atmospheric Environ. (Oxford, England : 1994), 45, 7555-7562, https://doi.org/10.1016/j.atmosenv.2010.12.021, 2011. Charrier, J. G. and Anastasio, C.: Rates of Hydroxyl Radical Production from Transition Metals and Quinones in a Surrogate Lung Fluid, Environ. Sci. Technol., 49, 9317-9325, https://doi.org/10.1021/acs.est.5b01606, 2015. 2016

Chen, X., Zhong, Z., Xu, Z., Chen, L., and Wang, Y.: 2',7'-Dichlorodihydrofluorescein as a fluorescent probe for reactive oxygen species measurement: Forty years of application and controversy, Free Radic Res, 44, 587-604, https://doi.org/10.3109/10715761003709802, 2010.

Cho, A. K., Sioutas, C., Miguel, A. H., Kumagai, Y., Schmitz, D. A., Singh, M., Eiguren-Fernandez, A., and Froines, J. R.: Redox activity of airborne particulate matter at different sites in the Los Angeles Basin, Environ. Res., 99, 40-47, https://doi.org/10.1016/j.envres.2005.01.003, 2005.

Delfino, R. J., Sioutas, C., and Malik, S.: Potential role of ultrafine particles in associations between airborne particle mass and cardiovascular health, Environ. Health Perspect., 113, 934-946, https://doi.org/10.1289/ehp.7938, 2005. 

and oxidative potential of air pollutant particles in a pediatric asthma panel, J Expo Sci Environ Epidemiol, 23, 466-473, https://doi.org/10.1038/jes.2013.25, 2013. Substances in Atmospheric Aerosols: Enhancement Effects by Pyridine, Imidazole, and Their Derivatives, Environ. Sci. Technol., 49, https://doi.org/10.1021/es5059378, 2015. Atmospheres, 105, 3565-3571, https://doi.org/10.1029/1999jd901070, 2000.

Eiguren-Fernandez, A., Kreisberg, N., and Hering, S.: An online monitor of the oxidative capacity of aerosols (o-MOCA), Atmos Meas Tech, 10, 633-644, https://doi.org/10.5194/amt-10-633-2017, 2017. Fang, T., Guo, H., Zeng, L., Verma, V., Nenes, A., and Weber, R. J.: Highly Acidic Ambient Particles, Soluble Metals, and Oxidative Potential: A Link between Sulfate and Aerosol Toxicity, Environ. Sci. Technol., 51, 2611-2620, https://doi.org/10.1021/acs.est.6b06151, 2017. quantifying the oxidative potential of ambient particles in aqueous extracts using the dithiothreitol (DTT) assay: Results from the Southeastern Center for Air Pollution and Epidemiology (SCAPE), Atmos Meas Tech Discussions, 7, 7245-7279, https://doi.org/10.5194/amtd-7-7245-2014, 2014. 2016.

Ghio, A. J., Carraway, M. S., and Madden, M. C.: Composition of air pollution particles and oxidative stress in cells, tissues, and living systems, J. Toxicol. Environ. Health. Part B, Critical reviews, 15, 1-21, https://doi.org/10.1080/10937404.2012.632359, 2012.

Guo, Z., Guo, Q., Chen, S., Zhu, B., Zhang, Y., Yu, J., and Guo, Z.: Study on pollution behavior and sulfate formation during the typical haze event in Nanjing with water soluble inorganic ions and sulfur isotopes, Atmos Res, 217, 198-207, https://doi.org/10.1016/j.atmosres.2018.11.009, 2019.

Hedayat, F., Stevanovic, S., Miljevic, B., Bottle, S., and Ristovski, Z.: Review - Evaluating the molecular assays for measuring the oxidative potential of particulate matter, Chem Ind Chem Eengq, 21, 31-31, https://doi.org/10.2298/CICEQ140228031H, 2014.

Hellack, B., Quass, U., Nickel, C., Wick, G., Schins, R. P. F., and Kuhlbusch, T. A. J.: Oxidative potential of particulate matter at a German motorway, Environ Sci Process Impacts, 17, 868-876, https://doi.org/10.1039/c4em00605d, 2015.

Huang, W., Zhang, Y., Zhang, Y., Zeng, L., Dong, H., Huo, P., Fang, D., and Schauer, J. J.: Development of an automated sampling-analysis system for simultaneous measurement of reactive oxygen species (ROS) in gas and particle phases: GAC-ROS, Atmospheric Environ., 134, 18-26, https://doi.org/10.1016/j.atmosenv.2016.03.038, 2016.

Janssen, N. A., Strak, M., Yang, A., Hellack, B., Kelly, F. J., Kuhlbusch, T. A., Harrison, R. M., Brunekreef, B., Cassee, F. R., Steenhof, M., and Hoek, G.: Associations between three specific a-cellular measures of the oxidative potential of particulate matter and markers of acute airway and nasal inflammation in healthy volunteers, Occup Environ Med, 72, 49-56, https://doi.org/10.1136/oemed2014-102303, 2015.

Li, Y., Zhu, T., Zhao, J., and Xu, B.: Interactive enhancements of ascorbic acid and iron in hydroxyl 

https://doi.org/10.1021/es301834r, 2012. inflammatory impacts of source apportioned ambient air pollution in Beijing, Environ. Sci. Technol., 48, 12920-12929, 10.1021/es5029876, 2014. Huang, T., Xu, Z., Bao, M., Zhang, W., Fan, M., and Lee, X.: Chemical and optical properties of carbonaceous aerosols in Nanjing, eastern China: regionally transported biomass burning contribution, Atmos. Chem. Phys., 19, 11213-11233, https://doi.org/10.5194/acp-19-11213-2019, 2019. Lodovici, M. and Bigagli, E.: Oxidative stress and air pollution exposure, J. Toxicol, 2011, 487074, https://doi.org/10.1155/2011/487074, 2011. by Engineered Nanomaterials: Evaluation of Acellular DCFH Assay, Dose Response, 10, 308-330, https://doi.org/10.2203/dose-response.10-036.Pal, 2012. Bolzacchini, E.: PM chemical composition and oxidative potential of the soluble fraction of particles at two sites in the urban area of Milan, Northern Italy, Atmospheric Environ., 128, 104-113, https://doi.org/10.1016/j.atmosenv.2015.12.040, 2016.

Pöschl, U. and Shiraiwa, M.: Multiphase chemistry at the atmosphere-biosphere interface influencing climate and public health in the anthropocene, Chemical reviews, 115, 4440-4475, https://doi.org/10.1021/cr500487s, 2015.

Puthussery, J. V., Zhang, C., and Verma, V.: Development and field testing of an online instrument for measuring the real-time oxidative potential of ambient particulate matter based on dithiothreitol assay, Atmos. Meas. Tech., 11, 5767-5780, https://doi.org/10.5194/amt-11-5767-2018, 2018.

Rohrer, F. and Berresheim, H.: Strong correlation between levels of tropospheric hydroxyl radicals and solar ultraviolet radiation, Nature, 442, 184-187, https://doi.org/10.1038/nature04924, 2006.

Sameenoi, Y., Koehler, K., Shapiro, J., Boonsong, K., Sun, Y., Collett, J., Jr., Volckens, J., and Henry, C. S.: Microfluidic electrochemical sensor for on-line monitoring of aerosol oxidative activity, J. Am. Chem. Soc., 134, 10562-10568, https://doi.org/10.1021/ja3031104, 2012.

Stevanovic, S., Vaughan, A., Hedayat, F., Salimi, F., Rahman, M. M., Zare, A., Brown, R. A., Brown, R. J., Wang, H., Zhang, Z., Wang, X., Bottle, S. E., Yang, I. A., and Ristovski, Z. D.: Oxidative potential of gas phase combustion emissions - An underestimated and potentially harmful component of air pollution from combustion processes, Atmospheric Environ., 158, 227-235, https://doi.org/10.1016/j.atmosenv.2017.03.041, 2017.

Stieger, B., Spindler, G., van Pinxteren, D., Grüner, A., Wallasch, M., and Herrmann, H.: Development of an online-coupled MARGA upgrade for the 2\&thinsp; interval quantification of low-molecularweight organic acids in the gas and particle phases, Atmos. Meas. Tech., 12, 281-298, https://doi.org/10.5194/amt-12-281-2019, 2019.

Velali, E., Papachristou, E., Pantazaki, A., Choli-Papadopoulou, T., Planou, S., Kouras, A., Manoli, E., Besis, A., Voutsa, D., and Samara, C.: Redox activity and in vitro bioactivity of the water-soluble fraction of urban particulate matter in relation to particle size and chemical composition, Environ. Pollut., 208, 774-786, https://doi.org/10.1016/j.envpol.2015.10.058, 2016.

Visentin, M., Pagnoni, A., Sarti, E., and Pietrogrande, M. C.: Urban PM 2.5 oxidative potential: Importance of chemical species and comparison of two spectrophotometric cell-free assays, Environ. Pollut., 219, 
495 Vreeland, H., Weber, R., Bergin, M., Greenwald, R., Golan, R., Russell, A. G., Verma, V., and Sarnat, J.

496 A.: Oxidative potential of PM2.5 during Atlanta rush hour: Measurements of in-vehicle dithiothreitol (DTT) activity, Atmospheric Environ., 165, 169-178, https://doi.org/10.1016/j.atmosenv.2017.06.044, 4982017

499 Wang, J., Lin, X., Lu, L., Wu, Y., Zhang, H., Lv, Q., Liu, W., Zhang, Y., and Zhuang, S.: Temporal variation of oxidative potential of water soluble components of ambient $\mathrm{PM}_{2.5}$ measured by dithiothreitol (DTT) assay, Sci. Total Environ., 649, 969-978, https://doi.org/10.1016/j.scitotenv.2018.08.375, 2019. Wragg, F. P. H., Fuller, S. J., Freshwater, R., Green, D. C., Kelly, F. J., and Kalberer, M.: An automated online instrument to quantify aerosol-bound reactive oxygen species (ROS) for ambient measurement and health-relevant aerosol studies, Atmos. Meas. Tech., 9, 4891-4900, https://doi.org/10.5194/amt-94891-2016, 2016. Environ. Sci. Technol., 51, 6507-6514, https://doi.org/10.1021/acs.est.7b01272, 2017. R., and Janssen, N. A. H.: Measurement of the oxidative potential of $\mathrm{PM}_{2.5}$ and its constituents: The effect of extraction solvent and filter type, Atmospheric Environ., 83, 35-42, https://doi.org/10.1016/j.atmosenv.2013.10.049, 2014.

513 Yu, S., Liu, W., Xu, Y., Yi, K., Zhou, M., Tao, S., and Liu, W.: Characteristics and oxidative potential of 514 atmospheric $\mathrm{PM}_{2.5}$ in Beijing: Source apportionment and seasonal variation, Sci. Total Environ., 650, 515 277-287, https://doi.org/10.1016/j.scitotenv.2018.09.021, 2019.

516 Zhang, C., Yang, C., Liu, X., Cao, F., and Zhang, Y.-1.: Insight into the photochemistry of atmospheric oxalate through hourly measurements in the northern suburbs of Nanjing, China, Sci. Total Environ., 719, 


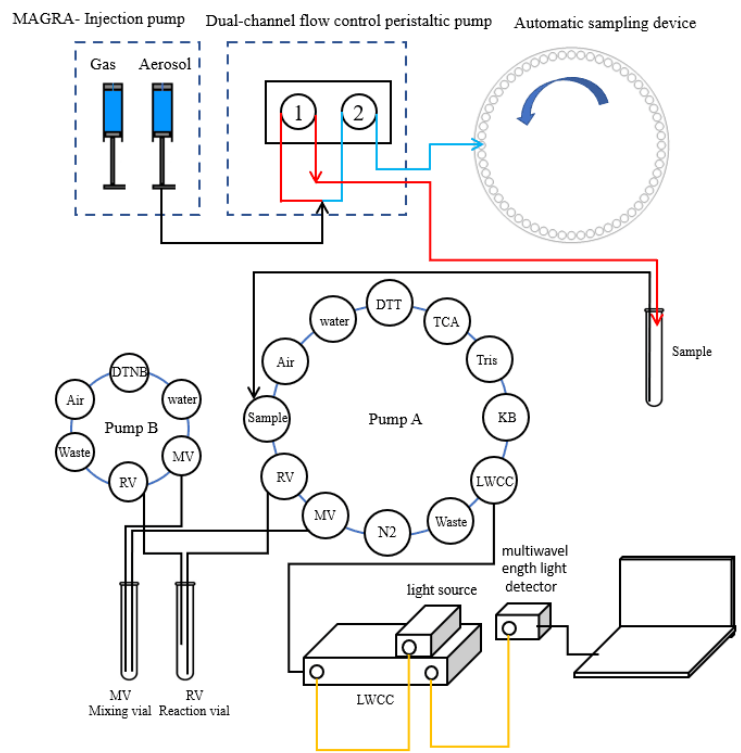

Figure 1. Automated system setup (Red line: Peristaltic pump 1 runs at a flow rate of $23 \mathrm{ml} \mathrm{h}^{-1}$ for the first 4 minutes of each hour; Blue line: Peristaltic pump 2 runs at a flow rate of $27 \mathrm{ml} \mathrm{h}^{-1}$ for the remaining 56 minutes of each hour; Yellow line: Optical fiber)
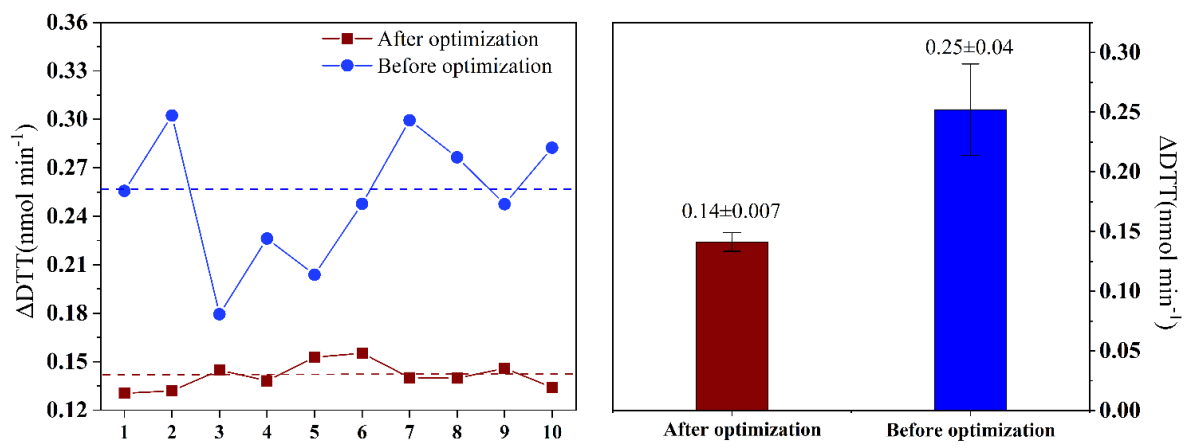

Figure 2. Comparison of blank DTT consumption rate and standard deviation after system 


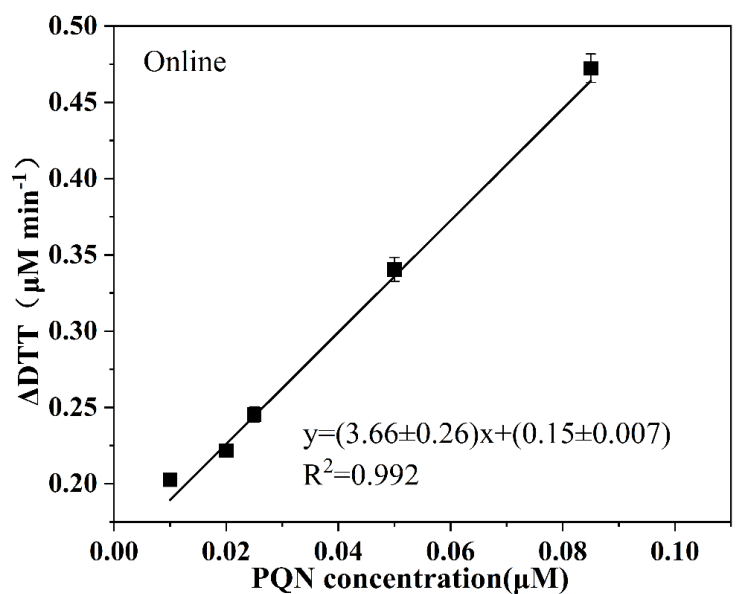

Figure 3. Blank corrected DTT consumption rate as a function of PQN used as a positive control. Each error bar represents the standard deviation of three independent DTT measurements on each concentration.

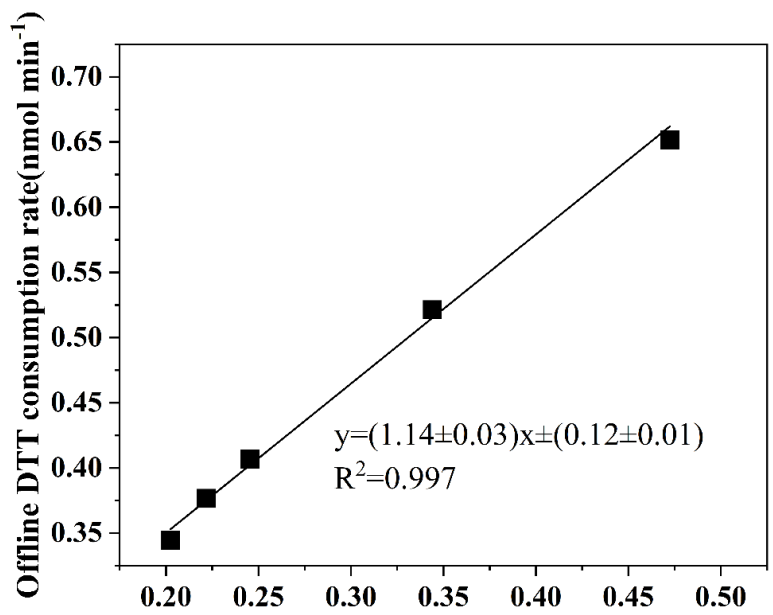

Figure 4. Comparison of the automated system with manual operation using PQN $(9,10-$ phenanthraquinone) 


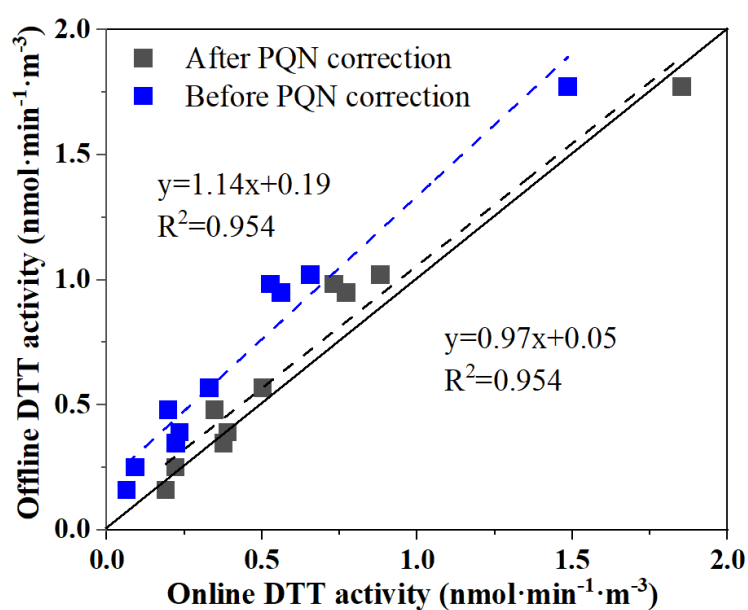

Figure 5. Comparison of the automated system with manual operation using ambient aerosol extracts ( $\mathrm{PM}_{2.5}$ samples collected from Xuzhou, regression analysis is done by orthogonal regression; the line is $1: 1$ ).

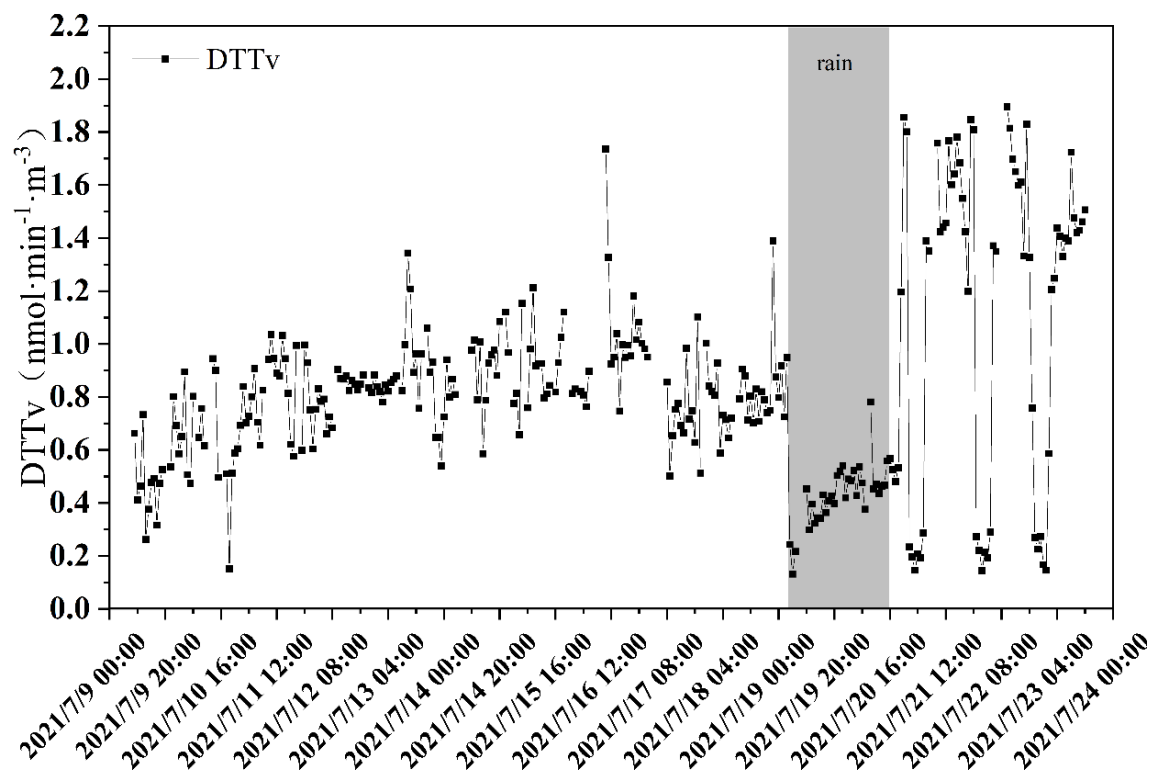

Figure 6. Time-series plot of the DTT activity, the shaded part in the figure is the measurement of DTT activity under heavy rain. 


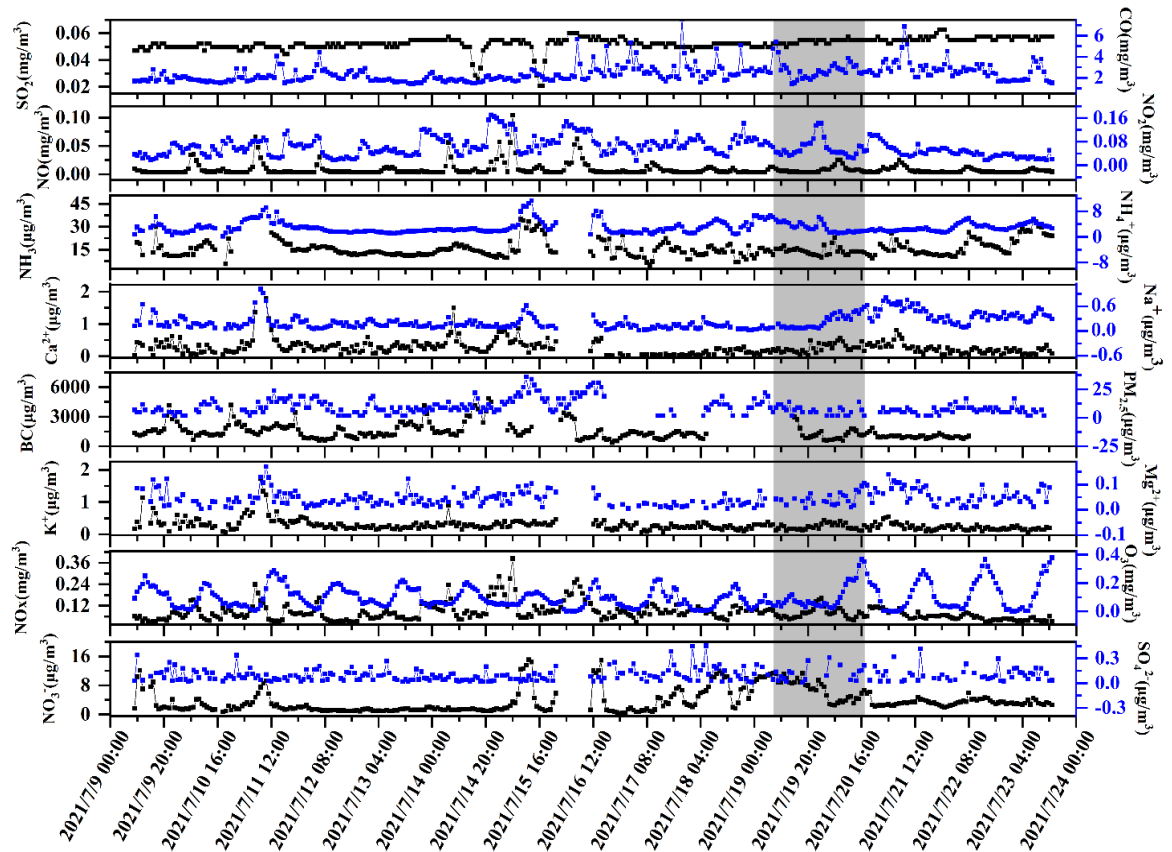

Figure 7. Time series of $\mathrm{PM}_{2.5}$ water-soluble components $\left(\mathrm{SO}_{4}^{2-}, \mathrm{NO}_{3}^{-}, \mathrm{NH}_{4}^{+}, \mathrm{Na}^{+}, \mathrm{Ca}^{2+}, \mathrm{K}^{+}\right.$) and polluting gases $\left(\mathrm{SO}_{2}, \mathrm{CO}, \mathrm{O}_{3}, \mathrm{NH}_{3}\right)$ (The shaded part is rainy weather)

Table 1. The correlation coefficient $(\mathrm{R})$ between the concentration of water-soluble chemical substances in environmental $\mathrm{PM}_{2.5}\left(\mu \mathrm{g} \mathrm{m}^{-3}\right)$ and the volume normalized substance concentration $\left(\mathrm{DTT}_{\mathrm{V}}\right)$, before rain, during rain, and after rain.

\begin{tabular}{ccccc}
\hline Parameter & Total & Before it rains & During rain & After rain \\
\hline $\mathbf{P M}_{2.5}$ & 0.014 & $0.305^{* *}$ & 0.026 & $-0.290^{*}$ \\
$\mathbf{S O}_{2}$ & $0.195^{* *}$ & 0.114 & -0.136 & 0.222 \\
$\mathbf{N O}$ & -0.029 & -0.029 & -0.074 & 0.050 \\
$\mathbf{N O}_{2}$ & -0.098 & 0.115 & 0.169 & -0.203 \\
$\mathbf{N O}_{\mathbf{x}}$ & -0.085 & 0.062 & 0.142 & -0.169 \\
$\mathbf{C O}$ & -0.033 & $0.146^{*}$ & -0.093 & 0.121 \\
$\mathbf{O}_{3}$ & $0.227^{*}$ & 0.153 & 0.044 & $0.624^{* *}$ \\
$\mathbf{B C}$ & -0.052 & -0.054 & $-0.439 *$ & 0.087 \\
$\mathbf{N H}_{3}$ & $0.241^{* *}$ & 0.074 & -0.129 & $0.269^{*}$ \\
$\mathbf{S O}_{4}{ }^{2-}$ & -0.06 & -0.065 & 0.329 & 0.028 \\
$\mathbf{N O}_{3}^{-}$ & $-0.163^{*}$ & $-0.155^{*}$ & $-0.352^{*}$ & $0.511^{* *}$
\end{tabular}


https://doi.org/10.5194/amt-2021-407

Preprint. Discussion started: 11 January 2022

(c) Author(s) 2022. CC BY 4.0 License.

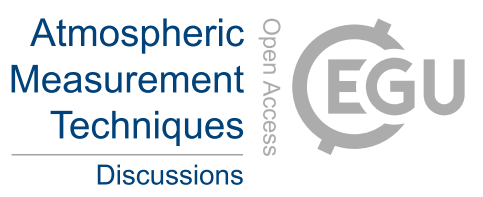

Discussions

551

$\begin{array}{ccccc}\mathbf{N H}_{4}{ }^{+} & 0.024 & 0.028 & 0.062 & 0.271^{*} \\ \mathbf{K}^{+} & -0.077 & -0.045 & 0.125 & -0.337^{* *} \\ \mathbf{M g}^{2+} & 0.131^{*} & 0.075 & 0.233 & 0.086 \\ \mathbf{C a}^{2+} & 0.005 & 0.072 & 0.021 & -0.055 \\ \mathbf{N a}^{+} & 0.177^{* *} & -0.007 & 0.133 & 0.008\end{array}$

550

$\mathrm{PM}_{2.5}$, particulate matter with an aerodynamic diameter $<2.5 \mu \mathrm{m} ;{ }^{*} \mathrm{P}<0.05,{ }^{*} * \mathrm{P}<0.01$ 